\title{
Teaching for Student Learning: Exploration of Teaching Strategies Based on Protocol-Guided Learning
}

\author{
Jianping Xia \\ Zhenjiang Experimental School, Zhenjiang 212000, Jiangsu, China
}

\begin{abstract}
The teaching strategy based on the case study guide is based on the case study guided, with teachers as the mainstay, students as the main body, and teacher-student working together to complete the teaching tasks, which is in line with Chinese education characteristics of localized teaching strategies. This teaching strategy advocates coordinating the relationship between various elements of teaching, so that teachers, students, and teaching materials maintain a coordinated state. We herein prospect through a case of a middle school in Jiangsu, China to explain the basic content of the teaching strategy, and analyze the practical exploration of the teaching strategy based on the protocol-guided study.
\end{abstract}

Keywords: Teaching Strategy; Protocol-Guided Learning; Protocol- guided Teaching Strategy; Teaching Practice; Zhenjiang Experimental School

About the Author: Jianping Xia, Principal, Advanced Teacher, Principal, Zhenjiang Experimental School, Zhenjiang 212000, Jiangsu, China. Email: xwph123@163.com.

Conflict of Interests: None. 


\section{Question}

$\mathrm{T}$

EACHING strategies can also be referred to as generalized teaching methods ( $\mathrm{Pi}$, 2000), which are "teaching program plans and teaching implementation needs in specific teaching situations" (Zhang \& Yu, 1996 ).

In 1964, Taba and other scholars proposed that teaching strategies should be used in the teaching process to motivate students to produce creative thinking (Taba et al., 1964). Since then, studies on teaching strategies had begun to attract attention and developed rapidly with emergence of different teaching strategies such as demonstrations, imitation teaching methods, five-segment teaching methods, mastery learning teaching strategies, and situation-ceramic teaching strategies, nine-segment teaching strategies, scaffolding teaching strategies, random entry strategies, and collaborative teaching strategy, etc. (Wei \& Wo, 2006). These strategies have guided and helped students' learning to a certain extent, and have exerted a positive impact on school teaching activities.

Teachers, students, and teaching content are the main constituent elements of teaching. There is a fierce discussion on which element should be centered in the formulation of teaching strategies, and corresponding different teaching strategies are proposed.

\section{Teacher-Centered Teaching Strategies}

The teacher-centered teaching strategy emphasizes the central position of teachers, the transfer of systematic knowledge, the role of classroom teaching, and the importance of teaching materials. As a result, the traditional education centers on teachers, classrooms and teaching materials (Zhang, 2007). This type of teaching strategy attaches importance to knowledge transfer, teaching methods and teaching results, and provides a solid path for students' basic knowledge learning. It is advocated that students acquire knowledge through teaching materials presented by teachers.

In the 1630s, Czech educator Comenius pioneered the teacher-centered teaching structure in The Great Pedagogy, supplemented by generations of educators and educational psychologists throughout the ages to make continuous exploration in this field. In-depth, the research results of teaching theory are also endless. The most representative is the "five-segment teaching method" proposed by the traditional school of education represented by Herbart. After the transformation of the former Soviet educator Kairov in the 20th century, a new five-segment teaching method was proposed, that is: motivating learning, reviewing old lessons, teaching new lessons, using consolidation, and checking results ( $\mathrm{Lu}, 1985)$.

This type of teaching strategy has dominated classroom teaching methods for a long time, especially Herbart's five-stage teaching method, which has had a profound influence in China (Hong, 1997). The five-segment approach almost became synonymous with Herbartian pedagogy in China at that time (Li, 2012). However, because of 
the five-segment teaching method of "emergency first," the learning attitude is often "learning from one person to another", and there is no time to introduce it at the academic level. As a result, the five-segment teaching method finally turned to the old model, which caused the negative phenomenon that "teachers can enter the classroom without writing lessons" (Dong \& Shi, 1991).

\section{Student-Centered Teaching Strategies}

Since the beginning of the twentieth century, students-centered teaching strategies have been proposed for scholars, such as Dewey, in traditional teaching strategies. From the "child-centered" and "activity-centered" advocated by Dewey (Ding, 2001), to the 1950s and 1960s Bruner vigorously promoted "discovery learning". Its core idea is also Encourage students to study and explore independently. In the 1990s, radical constructivism represented by Jonathan and characterized by subjectivism further emphasized the idea of "student-centered" and advocated all should be "student-centered" (Cui, 2003).

This kind of teaching strategy tends to the theoretical point of view of constructivist learning, that students are the subject of cognition and the active builders of the meaning of knowledge. Students should be the center of teaching activities, dominate and play a decisive role in education and teaching. The student-centered teaching strategy is a teaching strategy that advocates based on the laws of children's physical and mental development, and that students should be the center of teaching activities. It emphasizes student initiative and existing knowledge and experience. However, students have a certain degree of initiative, but they cannot replace their subjectivity with their initiative. Blind respect for students may also lead to classroom teaching not being carried out in an orderly and normal manner (Ren \& Xu, 2011).

\section{Student-Oriented and Teacher-Led "Dual-Master" Teaching Strategy}

With the change of international educational technology and educational ideas, the student-centered strategy with constructivism as the core idea has been questioned in the Western education world, and it has developed into increasingly fierce criticism and accusation. Some thought that teaching is always a dialectical unity of teacher's teaching and student's learning. It is a bilateral activity process, not a combination of two activity processes. However, those who support student-centered teaching said that the teaching process was mechanically divided into teaching activities and student learning activities, which violated the nature of the teaching process (Luo et al., 2012). Therefore, some have proposed the teaching strategy of the "dual-master" model (He, 1998), which is "the product of the compromise between the two". It is necessary to let the leading role of teachers play a role and fully reflect students' recognition to understand the role of the subject, and it is necessary to combine the advantages of the two to avoid the negative impact of both (Liu, 2008). 
Teaching is a complex process. It is not only constrained by the three basic elements of students, teachers, and teaching materials, but also by various factors such as teaching methods, teaching environment, and teaching organization. To ensure the normal operation of the teaching system, the various elements constituting the teaching system should be coordinated with each other, so that a general balance is maintained between the various elements. All elements of teachers and students, teaching and learning, knowledge and abilities, content and methods, in- and out-of-class learning should be coordinated. It is inappropriate to deliberately emphasize student-oriented or teacher-led, separate student learning and teacher teaching, the coordination of opposing knowledge and abilities, and blocking in-class and out-of-class.

The formulation of teaching strategies should also be based on a balanced perspective and consider the development of multiple factors. How to coordinate the relationship between the various elements of teaching and seek a balance between the elements is a topic of common concern to educators around the world. Chinese basic education practitioners have concluded an effective balanced teaching strategy in the longterm teaching practice-a teaching strategy based on the protocol-guided learning.

The teaching based on the protocol-guided learning plan is based on the case study as the carrier of learning and teaching, and as the method of teacher's guidance. This learning strategy pays attention to the guidance of learning methods, focuses on the formation of students' autonomous learning ability, implements the cultivation of core academic literacy, and focuses on cultivating and developing students' thinking habits and learning ability (Xiong, 2019). On this basis, many schools in China Using this as a template, creatively put forward new teaching modes in practice, such as the " $10+35$ " mode of Dulangkou Middle School, the "271" mode of Changle No. 2 Middle School, and the "recycling big classroom" mode of No. 1 Middle School, Xia Zhen No. 1 Middle School's "self-learning, doubt-solving, and reaching the goal" teaching mode (Li, 2011).

Zhenjiang Experimental School began to reform the school's classroom teaching based on the protocol-guided teaching model in 2005. Based on the reality of the school, a school-based guidance plan has been developed, and classroom teaching strategies based on the guidance plan have been implemented through multiple reforms. After many years of implementation and application, the school's high school entrance examination score has ranked first in its municipality for 14 consecutive years, and has twice won the first prize of teaching achievements in Jiangsu Province. The radiation range of its teaching reform results has ranged from the school's Runzhou District, Zhenjiang City, Jiangsu Province and many provinces across the country.

\section{Research Status}

The teaching strategy based on the protocol-guided learning plan is the basis, using the study guide as the method, the teacher's guidance as the lead, the students' autonomous learning as the main body, and the teachers and students working together to complete 
the teaching task, which is in line with Chinese educational characteristics Localized teaching strategies (Luo, 2016).

As a localized teaching strategy in China, the research on teaching strategies based on protocol-guided learning is mainly located in the mainland of China. At the end of the 1990s, Donglu Middle School in Lishui District, Nanjing, Jiangsu Province pioneered the "lecture draft", which was also the first time that students' materials had been written from the perspective of students, and the reform of classroom teaching had been carried out accordingly (Tao, 2013). The birth of the "lecture draft" changed the structure of classroom teaching and provided students with materials for autonomous learning, making it possible for students to learn independently (Yang, 2016). With the start of the new curriculum reform, student-centered thinking has been further established, and the "lecture draft" has evolved into a "lead draft" or "learning plan". Teaching based on the study guide has gradually become an effective teaching method leading the new curriculum of elementary education in elementary and middle schools (He, 2014).

With the deepening of the research, the research on the teaching strategy based on the protocol-guided learning mainly focuses on two aspects, namely theoretical research and practical research.

Theoretical researchers mainly discuss the teaching model of the protocolguided learning from the theoretical aspect. For example, Yanan Pei summarized the teaching model of the teaching case from the theoretical basis, teaching objectives, operating procedures, teacher and student roles, etc. "Teaching, tutoring, sublimation" teaching mode in four basic stages (Pei, 2007). Zhang \& Zheng used the background of educational informatization to explain the theoretical basis. He believed that on the basis of self-regulated learning theory, personalized teaching concepts, recent development zone theories, and the characteristics of middle school students, the implementation of educational practices must be differentiated and flexible The basic principles of sexuality, participation, and stratification of goals (Zhang \& Zheng, 2016). In addition, many similar teaching methods derived from the case study teaching have also attracted the attention of researchers, such as the "2223 efficient classroom" teaching method, " 1215 " interactive teaching method, " 271 " efficient classroom method, etc., scholars It is believed that these teaching methods are designed to use student-led teaching to cultivate students' autonomous learning, cooperative communication, experimental operation ability, guide students to explore problems, and handle the relationship between "teaching" and "learning" (Jia, 2017).

The front-line teachers have explored the specific operation of protocol-guided teaching from the perspective of their own disciplines. For example, Haowen Ma takes the physics discipline in middle school as an example, and discusses the practical significance and methods of implementing protocol-guided teaching strategies in physics discipline. It is believed that the protocol-guided method of the case can enable students to complete self-study before class, cultivate students' self-study ability, promote students to enter the learning state quickly, and improve teaching efficiency (Ma, 2019). Focusing on the design and implementation of protocol-guided learning in high school 
English, Mao expounded the content of using middle school English in case study teaching, raised common questions, and specifically described the English teaching in six aspects Strategy implementation measures. Thus, it is concluded that "using protocol-guided learning for English teaching can improve the teaching effect of English classrooms and improve students' autonomous learning ability, attitude, and methods" (Mao, 2019).

Although there is no clear definition of teaching strategies based on protocolguided learning in foreign countries, the mainstream educational strategies advocated by foreign researchers are consistent with the teaching strategies mentioned in this research in terms of guiding ideology and educational significance. Rugen Genschein's "Practice Teaching Method" emphasizes the study of special examples to infer the general characteristics of the development of the same kind of things, so as to grasp the development law of this kind of things and improve students' objective understanding of things (Jia, 2017). The scaffolding teaching strategy advocates that children with the help of teachers eliminate the gap between the actual level of development (the first level of development) and the potential level of development (the second level of development) when solving problems independently (Helen Askell-Williams et al., 2012). Anchor teaching strategies are based on real-life examples or problems, and encourage learners to enter the real environment to feel and experience (that is, learn by acquiring direct experience), rather than just listening to others (such as teachers) about this experience and explain. The random entry teaching strategy advocates that learners can freely enter the learning of the same teaching content in different ways, so as to obtain multiple aspects of the same thing or the same problem. These teaching strategies emphasize "student-centered", establish students 'subjective status, and focus on developing students' initiative and enthusiasm (Mehdi et al., 2016). This coincides with the core idea of teaching strategy based on protocol-guided learning.

\section{The Basic Meaning of Teaching Strategy of Protocol- Guided Learning}

The teaching strategy based on protocol-guided learning is to consider teaching as a complete system, to coordinate the relationship between various elements of teaching, and to maintain a relative balance between teachers and students, teaching and learning, and intra- and extra-curricular elements. Teachers compile texts of student's learning and teacher's teaching (collectively referred to as protocol-guided learning in this article) based on curriculum standards, textbook content, and students' cognitive status. Teaching students how to learn by protocol is the major activity of this protocol-guided learning.

This teaching strategy emphasizes the perfect combination of student-oriented and teacher-led activities. On the one hand, it emphasizes that student-centered learning is the center of the teaching process, and that learning is a matter for the students themselves. This advocates that all learning should take place on students and give full play to their main role. On the other hand, in the teaching process, the role of teachers in 
students' learning process is emphasized. Students must be guided, guided and counseled by teachers in order to carry out their studies better. Teachers guide students to preview before class, guide (induct) students to study during the class, and to consolidate students after class to give full play to teachers' leading role.

Learning is fundamentally a matter for students. Teaching activities should stimulate students' internal driving force so that learning really takes place on the students themselves. The student's learning path designed under this guidance should be goal-oriented, problem-centered, and premised on self-preparation. Combining selfinquiry and intensive lectures should be supported by on-site training to promote generation in class ( $\mathrm{Li}, 2019)$.

- Learning goal-oriented: change the teaching goal to the learning goal of the students, and let the students identify the learning tasks that need to be completed in each lesson.

- Problems as the core: The knowledge of middle school students in textbooks is transformed into problems that students need to solve, and students are led to learn through problems. This is the core of protocol-guided learning teaching.

- Self-study is the premise: Students self-study part of the protocol-guided learning pre-class, and complete related supporting test exercises.

- The combination of self-inquiry and intensive instruction is the key: the simpler teaching content guides students to learn independently or cooperate in group learning; for the more complicated teaching content, the teacher will give accurate lectures and make the students understand What you have learned.

- Generation in class and on-the-spot training as a guarantee: the teacher guides the students to raise the problem-solving ideas and methods of this lesson to the principle of knowledge; the teacher guides the students to do the exercises in the classroom, and strengthens the knowledge learned through the in-class training.

The basic starting point of teaching based on protocol-guided learning is to coordinate the relationship between the elements of the teaching, and strive to maintain a good balanced relationship between the elements.

At the teacher level, the basic thinking of this strategy is problem protocolguided, teaching by learning, combining learning with thinking, and teaching and learning mutually reinforcing.

- Problem protocol-guided: Guide students to think and learn with specific problem presets, so that students have greater initiative and autonomy. High-quality question presets are essential to the formation of an efficient classroom. The so-called "problem" is not only the basic knowledge, but also the method and method, or the strategy of implementation and presentation from different perspectives (Jiang, 2019).

- Teaching based on learning: Teachers should be good at guiding, inspiring, associative, and inquiring questions from students, and students should think, act, try, experience, explore, and predict Then, according to the learning needs of 
students at different levels, determine the content of intensive talks, summarize and propose precautions, and guide students in a targeted manner (Zhao, 2017).

- Combination of learning and thinking: Let students think deeply and communicate about relevant issues in the classroom, promote students' further understanding and mastery of learning content, internalize into their own experience and knowledge structure, train students to ask questions, analyze questions, Problem-solving skills to enhance students' initiative and autonomy in learning (Liu, 2013).

- Teaching and learning are mutually reinforcing: protocol-guided learning includes not only student thinking and learning, but also teacher reflection and learning. While teachers are constantly improving the way knowledge is presented, teachers must also continue to think and improve. In the process of teaching and learning, teachers and students continue to grow and progress (Zheng, 2015).

\section{The Basic Content of Protocol-Guided Learning Teaching Strategy}

The basic steps of protocol-guided learning in different schools are different. The following describes the basic steps of the protocol-guided learning in Zhenjiang Experimental School as an example. The steps of protocol-guided learning are also different in different types of classroom teaching. For new courses, the teaching steps include nine basic steps: set up study goal, protocol-guided preview, autonomous cooperation, intensive analysis and lecturing, on-site practice, expansion and extension, induction and summarization, homework assignments, and questioning reflection (Xia, 2017).

\section{Set Up Study Goal}

According to the new curriculum standards and the students' cognitive level, the common goals of teachers and students in this lesson are determined, so that teachers and students form a strong sense of goals in the teaching and learning process.

\section{Protocol-Guided Preview}

Create situations or steps based on learning goals, and guide students to read, study, think, and explore independently, so that students can have a preliminary understanding of teaching materials through self-study before class, discover problems, and complete the first teaching.

\section{Autonomous Cooperation}

According to the learning objectives, with the help of textbooks and media, students autonomously or in groups to complete the learning of the basic concepts, basic graphics, and basic methods in the teaching content of this section, focusing on double- 
based learning and consolidating the foundation. At the end of the self-study, the students exchanged and discussed with the group of students, cooperated and explored, and complemented each other. On the basis of sharing the collective results, a comprehensive and correct understanding of the current knowledge is achieved, that is, the meaning construction of the learned knowledge is finally completed.

\section{Intensive Analysis and Lecturing}

The teacher selects typical examples, analyzes and lectures in class, inducts regular methods, and cultivates students' thinking ability. A basic exercise is configured after each example problem. After the analysis of the example problem, training is conducted in the classroom to achieve the effect of timely feedback and timely reinforcement, and complete the second teaching.

\section{On-Site Practice}

In order to understand the effect of classroom teaching, teachers choose appropriate amount and certain "texture" topics as feedback exercises for classroom teaching, so that teachers can "know what", the topic design should be closely related to production and life issues, and there should be some variant exercises It should not be too difficult. Deal with the student's achievement rate accordingly and prepare a lesson for the next lesson. At the same time, the problems exposed in the test should be evaluated and solved in the classroom without leaving "post-morbidities", so as to complete the third teaching.

\section{Expansion and Extension}

Requires extended relocation training, expands thinking, and enhances ability to use. Teachers mobilize their minds, morph their training, solve problems, and develop wisdom. Students concentrate their energy, think positively, discuss solutions, and share results to achieve a leap in teaching.

\section{Induction and Summarization}

According to the actual teaching situation, the teacher or student can summarize the classroom teaching, which can be a knowledge review or a talk about the harvest. Teachers should reveal the "mystery" to the students based on the discussions of the students and the content of the teaching materials, so as to form a correct knowledge theory.

\section{Homework Assignments}

Teachers arrange students' after-class learning tasks based on the characteristics of the subject and the tasks to be completed in the next lesson: (1) after-class consolidation: 
mainly comprehensive, open, and research-type questions to leave room for students to innovate. (2) The preview protocol-guided part of the next class teaching protocol.

\section{Questioning Reflection}

We require teachers and students to re-understand the teaching and learning experience in the classroom, which includes reflection on "the lost" and induction of "the gain" in order to implement secondary or multiple lesson preparation.

Take the teaching of the Seventh Edition of the People's Education Version of the book Multiplication of Powers of the Same Base as an example:

Teachers determine the students' learning goals before class, that is, correctly understand and apply the multiplicative rule of the power of the same base, and then establish the teaching goal of the teacher, even if the student understands the multiplicative rule of the power of the same base, and derive from the "multiplicative rule of the power of the same base" and application, preliminary understanding of special to general, general to special cognitive laws.

Students preview and complete the pre-reading assignments. Students can use the assignments to achieve the effect of the pre-reading texts. Teachers can also determine the key points of teaching based on the completion of the students' pre-reading assignments.

In the classroom teaching, the teacher creates a situation and derives the question "Let the students get the characteristics of the formula through observation: " $10^{5} \times$ $10^{7}="$, to guide students to study independently and group cooperation to explore the problem. In this process, teachers ask students to explain the reasons for each step according to their understanding of the meaning of power. According to the learning situation of the students, the teacher explains the selected examples and guides the students to summarize the calculation methods of the powers of the same number in the explanation, so as to cultivate the students' thinking of summing up the laws.

Teachers arrange students for on-the-spot training so as to consolidate in time. In the extended training, the teacher raised the difficulty and asked the students to observe and calculate the left and right sides of the formula and think about the relationship between the base and the index. Then encourage students to summarize the found laws in a relatively concise form, and ask students to explain, explain, and verify its correctness from the perspective of the meaning of power.

$$
10^{3} \times 10^{2}=10^{(?)}, 2^{3} \times 2^{2}=2^{(?)}, \mathrm{a}^{3} \times \mathrm{a}^{2}=\mathrm{a}^{(?)}
$$

The teacher leads the students to summarize and summarize the multiplication rule of the power of the same base, and arrange homework, which is mainly for the consolidation of the lesson content and the preliminary work for the subsequent content. After the class, teachers and students are required to reflect after class. The teacher reflects on the specific situation of this class. Students should self-reflection according to the learning situation, and achieve self-summary and self-remedy. Further, the extended 
homework assignments can be arranged in layers according to the student's academic situation to ensure that students with different academic situations can develop.

\section{Implementation of the Teaching Strategies in Proto- col-Guided Learning}

\section{Planning Teaching Arrangements and Restructuring the Teaching Process}

Teaching is a bilateral activity between teacher teaching and student learning. The development of teaching cannot be separated from teacher teaching. Emphasizing the main role of students in the teaching process does not exclude the leading role of teachers in the teaching process. The combination of student's subject and teacher's dominance is a rational state $(\mathrm{Hu}, 2011)$.

In the teaching process, the teacher's leadership is reflected in the guidance of the students' learning before the lesson, the guidance (induction) of the students' learning during the lesson, and the tutoring of the students' learning after the lesson. In the teaching process, teachers guide, guide, and guide students to learn. Without teacher guidance and guidance, students' learning is difficult to complete. Therefore, the successful implementation of teaching based on protocol-guided learning must reconstruct the teaching process.

\section{Prepare Lessons Carefully and Compile Excellent Protocol-guided Learning}

The teaching foundation based on protocol-guided learning is protocol-guided learning. To implement protocol-guided learning teaching, we must first prepare appropriate protocol-guided learning.

With reference to the meaning of protocol-guided learning in many literatures, we define protocol-guided learning as: primary and secondary school teachers based on curriculum standards and teaching materials, combined with students' academic situation and cognitive status, are guided by learning goals, and focus on problems learning materials as protocol to guide students before, during and after class (Xia, 2017).

Based on its meaning, we can determine the following writing principles:

First, adhere to the principle of student subjectivity or transposition. That is, the users of protocol-guided learning are mainly students, and should not be written from the perspective of teacher teaching but from the perspective of guided students' learning (Yi, 2003). Second, the appropriate principle, that is, the capacity and difficulty of protocol-guided learning should be appropriate. For example, the number of learning goals in a class must not be too much, the learning activities must not be too much, and the difficulty of the problem cannot exceed the students' cognitive level (Li \& Teng, 2011). Third, the problematic principle is to stimulate students to think in the form of problems (Li, 2011). Fourth, the principle of order or system, that is, the design of the entire protocol-guided learning content, especially the learning content and teaching process, 
must be logical, so that students can form a certain knowledge system after learning instead of only obtaining some fragmented knowledge (Li \& Teng, 2011).

The teaching strategy based on protocol-guided learning is a Chinese localized teaching strategy that embodies the collective wisdom of education researchers and front-line education practitioners. For example, the compilation of protocol-guided learning is the product of collective wisdom under China's collective lesson preparation system. Taking the protocol-guided learning writing process of Zhenjiang Experimental School as an example, the school first prepares the subject activity plan and classroom teaching research plan by the class preparation team leader, and compiles the team members' reasonable division of labor. Then the members of the subject administration and subject teaching research and guidance team are responsible for reviewing the master and backup drafts according to the division of labor. Finally, the teachers of each class flexibly modify the protocol-guided learning according to the class teaching progress and academic situation. In addition, the subject administration and preparation team leader will listen to the lessons in the classroom, focusing on listening to some teachers' lessons and key lessons, strengthening classroom teaching monitoring through listening, and implementing personal specialization of school classroom teaching through in-depth exchanges with teachers after the lecture.

\section{Revitalize the Classroom and Teach Well}

The core of the teaching strategy based on protocol-guided learning is to organize teaching with questions. In the teaching process, teachers use the problems in protocolguided learning as clues to teach, and the knowledge in textbooks is transformed into students' learning problems.

In the face of these problems, on the one hand, students can learn to solve them by themselves. Any problems that students can understand or students already understand will not be explained by teachers. Such problems will be left to students to learn independently or cooperatively. On the other hand, the teaching content of many disciplines, especially in the field of science, cannot be explored by the students themselves. Teachers need to explain them carefully. Some very important laws, such as the Law of Conservation of Mass in physics teaching, must be understood by the teacher's explanation of students (Liang, 2018).

The teacher's explanation must be based on the problem of protocol-guided learning, and through the teacher's explanation, the thinking process of solving the problem and the thinking of solving the problem are fully displayed to the students. The explanation is not a long story from the beginning to the end of the teacher. The focus of the explanation is on the dial. Teachers make appropriate assignments to the key points, difficult points, and error-prone points in the students' learning process. Do it in teaching: the teachers that the students have already met will no longer explain; the teachers who can learn by themselves will not explain; the teachers will not explain the "partial, difficult, strange" questions raised by individual students; the teachers will not repeat after the students answer the questions Speak; the teacher can explain clearly the 
student does not explain. As thus avoid turning your teacher's lecture into a simple exercise calculus.

\section{Combining “Reading, Thinking, Speaking, and Practicing”, Multiple Teaching Methods Work Together}

The teaching based on protocol-guided learning focuses on the collaborative use of multiple teaching methods. In the teaching process, try to reflect the combination of "reading, thinking, speaking, practicing", a variety of teaching methods work together. Zhenjiang Experimental School insists on "reading, thinking, speaking, and practicing" as its core, combining learning with teaching, and teaching by learning.

"Reading" refers to the reading of students, which highlights the students' overall perception and autonomy through reading. Reading is an important means for students to acquire knowledge, develop intelligence, and develop abilities. It is one of the main ways for students to acquire knowledge, and it is also one of the important methods for cultivating students' self-learning ability. Teachers should guide students to read, organize and deal with the teaching content, clearly ask questions that should be considered when reading, and let students read with questions. Grasp the key points to read, think while reading, and think while you read (Zhang, 2019).

"Thinking" refers to students 'thinking. Through thinking, students' inquiry ability can be cultivated to form the habit of cooperation and communication. Thinking allows students to constantly transform old appearances and create new ones based on the knowledge content and self-study effect of a class. "Thinking" is to think and discuss problems that you do not understand or do not understand during the process of "reading." "Thinking" includes both the students' individual thinking and the collective thinking of several students or a group of students. In the teaching process, students under the guidance of teachers, students, groups, teachers and students to think about and discuss the understanding of protocol-guided learning (Liang, 2016).

"Speaking" refers to the narration, explanation, and analysis of teaching content, so that students can further understand the content of teaching materials through narration and explanation. There are two parts to telling, explaining and analyzing. The first is student's speaking, where the students tell or analyze the ideas and results of solving problems raised by individual thinking or group discussion. The second is teacher's lectures. Teachers provide targeted explanations and analyses to enable students to achieve a high level of awareness of the ideas, concepts, and theories to be expressed in the problems of protocol-guided learning ( $\mathrm{Wu}, 2013)$.

This step is very important. The quality of the teacher's lectures directly affects the students' knowledge and skills. In the lecture, the teacher strives for the teacher to be familiar with the teaching materials and elaborate design. The structure is required to be systematic, organized, clear-cut, and the key points are difficult to highlight. Language needs to be clear, vivid, accurate, concise and vivid. At the same time, we must also pay attention to the level of emotional realization in classroom teaching, try our best to stimulate students' interest in learning, desire for knowledge, and motivate students' thinking enthusiasm. 
"Practicing" refers to students' homework training before, during, and after class. Through training, students can better master and apply what they have learned. The practice runs through the teaching process. Before the lesson, you can learn about the students' learning status through the practice of the test questions during the preview. In-class training is used to strengthen and consolidate the required knowledge in time. After class, the knowledge will be further strengthened through exercises. Here, special emphasis is placed on classroom training in classroom teaching. The exercises in the above stages achieve the "four completions" of teaching tasks, that is, "every lesson completion", "daily completion", "weekly completion", and "monthly completion" (Liu, 2009). The exercises should be centered on the focus of the textbook, systematic knowledge, and knowledge that is easy to make mistakes, easy to forget, and easy to confuse (Xia, 2017).

\section{Discussion}

The teaching strategy based on protocol-guided learning is based on protocol-guided learning, with teachers as the mainstay, students as the main body, and teachers and students working together to complete teaching tasks.

The teaching strategy based on protocol-guided learning advocates that teachers use protocol-guided learning, which is a student learning and teacher teaching material written from the standpoint of student learning to flexibly design and arrange teaching activities. The teaching process should be regarded as a whole, i.e., before, during and after class. Taking students 'learning activities as the mainline and evaluation as the means, based on the students' pre-class preview, teaching activities are carried out around the main line of students asking and solving problems, displaying learning results, summing up learning experiences, strengthening learning results, and expanding and extending learning content. Pay attention to the development of students, cultivate students' awareness and ability to discover problems independently, cooperate autonomously and explore problems in class, and allow students to give full play to their autonomy under the guidance of teachers.

The teaching strategy based on protocol-guided learning is an effective attempt to reform the classroom teaching of basic education in China. After being used by thousands of schools across the country for more than two decades, teaching strategies based on protocol-guided learning have been widely recognized ( $\mathrm{Hu}, 2015)$. Studies have shown that this teaching strategy can help students improve their academic performance and improve their learning ability. At the same time, it can also improve teachers 'teaching ability and teaching level, and teachers' professional growth. Many studies have proven that the implementation of protocol-guided learning in classroom teaching has improved classroom teaching efficiency and transformed classroom teaching methods (Teng, 2015). To a certain extent, protocol-guided learning teaching can be considered to represent the staged results of the implementation of quality education in China and a major event that marks the new curriculum reform of basic education ( $\mathrm{Yu}$ \& Shi, 2014). 
The teaching strategy based on protocol-guided learning also exposes some problems in practice. For example, in the training of top students, many schools report that this strategy is conducive to improving students' academic performance on a large scale, but not conducive to the growth of top students. There are critics who point out that this strategy limits the autonomy of teachers 'teaching and restricts teachers' autonomous teaching behaviors too (Qiu, 2017). In this regard, some researchers have proposed that Internet technology can be used to break the shortcomings of protocolguided learning in the cultivation of top students. Integrating modern technologies such as the Internet and big data analysis with the classroom to make up for the shortcomings of protocol-guided learning in improving excellence and better teaching and learning in a personalized way (He, 2019).

\section{References}

Cui, J.G. (2003) Review of Constructivist Education View. Contempo Edu Sci, (1): 9-11.

Ding, B.P. (2001) Constructivism and Science Education Reform Facing the 21st Century. Comp Edu Res, (8): 6-10.

Dong, Y.Z., Shi, Y.Y. (1991) Selected Works of Yu Ziyi's Education. Beijing: People's Education Press, 479

Gui, G.J. (2003) Application of the "protocol protocol-guided" model in middle school mathematics teaching. Shandong: Shandong Nor Univ.

He, K.K. (1998) Review on the Research of Instructional Design Theory and Method (Middle). Edu Theo Edu Manag, (03) 1926

He, K.K. (2019) Theory of Deep Integration of Information Technology and Curriculum: Effectively Realizing the Deep Integration of Information Technology and Subject Teaching (2nd Edition) Beijing: Beijing Nor Univ Press

He, L.L. (2014) Application of protocolguided in biology teaching in high school. Jinan: Shandong Nor Univ.

Helen, A.W., Michael, J., Lawson, G.S. (2012)

Scaffolding cognitive and metacognitive strategy instruction in regular class lessons. Instru Sci, 413-443

Hong, C. (1997) Herbart's five-step teaching method in China. Curr, Teach Mater Teach Meth, (05): 60-62

Hu, X.R. (2011) Reflection on the "protocolguided learning" teaching model. Xue Zhou Xue, (03): 13

Hu, X.T. (2015) The compilation strategy of protocol-guided learning based on classroom teaching. Middle School Physics, (08): 30-31

Jia, L.M. (2017) "One Two Five” autonomous classroom protocol-guided learning teaching mode in middle school biology teaching. Inner Mongolia: Inner Mongolia Nor Univ.

Jiang, X. (2019) Problem protocol-guided: Quiet Thinking Revolution. Inner Mongolia Edu, (35): 51-52

Li, B.T. (2011) Nine teaching paradigms of efficient classrooms (Department of Education Discovery). Jinan: Shandong Literature and Art Publishing House

Li, G.Y. (2019) A brief introduction to the middle school mathematics protocol protocol-guided teaching model of autono- 
mous learning protocol. Curr Edu Res, (31): 152

Li, K., Teng, J.P. (2011) Talking about the establishment of "learning protocol" and "learning protocol". Chin Teach, (23): 4345

Li, L.F. (2012) Herbart's five-step teaching method in China: introduction, dissemination and inspiration. J Shandong Yingcai Univ, (01): 34-37

Li, T.F. (2011) How to write practical and effective protocol-guided learning. Qinghai Edu. (11): 43-44

Liang, C.J. (2016) Guided learning to practice and promote thinking-the practice and thinking of protocol-guided learning. Middle school mathematics (high school version) the first half of the month, (07): 25-27

Liang, H. (2018) Reflection and Analysis on the "protocol-guided learning" Teaching Mode. Math Learn Res, (02): 73

Liu, J.Y. (2009) "Learning first, then teaching, training in the classroom": Solving five major problems - - Analysis of Jiangsu Yangsi middle school classroom teaching strategy. Prim Mid School Manag, (05): 16-19

Liu, S.H. (2013) Using protocol-guided learning to construct a teaching mode of "thinking by learning, combining evaluation with practice". Liter (Edu Teach Res), (26): 51

Liu, X.L. (2008) The enlightenment of the "dominant-subject" teaching mode to the teaching of "University Chinese". China Sci Educ Innova Guide, (01): 121.

Lu, J. (author) (1985) Department of Education, Nanjing Normal University (ed.) Education. Beijing: People's Education Press

Luo, S.Y., Wang, S.N., Shao, M.Z. (2012) On the unity of opposites between traditional and constructivist views of learning. $\mathrm{J}$ Dongguan Univ Tech, 19 (2): 22-25

Luo, W. (2016) Probe into the protocol-toguided classroom teaching mode. Gansu Edu, (20): 77

Ma, H.W. (2019) Application of protocol-toguided method in middle school physics teaching. Curr Edu Res, (41): 161-162
Mao, F.F. (2019) Study on the value of the protocol-guided method in middle school English teaching. Eng. Wide Angle, (05): 157-158

Mehdi, E., Francesco, R., Neil, R. (2016) A survey of active learning in collaborative filtering recommender systems. Comp Sci Rev, 29-50.

Pei, Y.N. (2007) Summary of the protocol-toguided teaching model. J Inner Mong Nor Univ (Edu Sci Edition), 20 (04): 66-69.

Pi, L.S. (2000) Psychology of Intellectual Education [M]. Beijing: People's Education Press.

Qiu, T.Z. (2017) "Pros and Cons of Mathematical Protocol-guided Learning". Liberal Arts Navigation, (3) 62-63

Ren, D.D., Xu, Y.Y. (2011) The rationality and limitations of the teacher-centered and student-centered theory and their integrated development trends. J Xingtai Univ, (1): 45-47

Taba, H.E., Freeman, F. (1964) Teaching strategies and thought processes. Teach College Rec, 65 (6): 524-534.

Tao, J. (2013) Research on the application of the "lecture draft" mode in the middle school moral and moral lesson. Jiangsu: Suzhou Univ.

Teng, F. (2015) Application of the protocolto-guided teaching model in biology teaching in high school. Harbin: Harbin Nor Univ.

Wei, Y.P., Wo, J.Z. (2006) Trends in Teaching Strategy Research: Development of Subject Teaching Strategies. J Guangxi Nor Univ: Philo Soc Sci Edition, (42): 105-110

Wu, J.H. (2013) Height • Gradient • Validity: A Preliminary Study of the "Protocolguided, Intensive Lecture, and Diligent Practice" Teaching Mode. Middle School Polit Teach Refer, (10): 50-51

Xia, J.P. (2017) School-based Action Research on Student Self-development in the Perspective of Whole Person Education. Zhenjiang: Jiangsu Univ Press, 13-15、 123-145.

Xiong, H.X. (2019) Compilation and Application of Protocol-guided Learning for High 
School Biology Review Courses in the " 3 +3" New College Entrance Examination. Shanghai: Shanghai Nor Univ.

Yang, X.M. (2016) Make good use of the teaching method of lecture draft to create an efficient mathematics classroom: an example of the effectiveness of middle school mathematics classroom teaching. Mingshi Online, (09): 33-34.

Yu, H.L., Shi, Y.H. (2014) On the essence of protocol-guided learning and its enlightenment to teacher education. Curr Teach Method Teach Mater,34 (8): 110-115.

Zhang, B.M., Zheng, H.F. (2016) Protocolprotocol-guided Teaching Mode: Theory, Practice and Prospect. J Jilin Pro Insti Edu, (07): 117-120

Zhang, D.J., Yu, L. (1996) On the basic meaning of teaching strategies and the ba- sis for their formulation. Curr,Teach Mater Teach Methods, (9): 6-8

Zhang, Q.H. (2019) A Brief Discussion on the Protocol-guided, Guided Practice and Guided Reading in the Teaching of Mathematical Analysis.

Zhang, Y. (2007) Research on the "nonindicative" reading teaching model of high school under the new curriculum background. Jilin: Northeast Nor Univ. Zhao, Q. (2017) Protocol-protocol-guided highlights teaching and learning. Edu (Weekly), (21): 53

Zheng, Y.Y. (2015) Learning-oriented and Teaching Demonstration—-The Application and Thinking of Middle School History Protocol-guided Learning. Polit History Geogra Teach Res, (43): 133-134.

Received: 29 January 2020 Revised: 05 February 2020 Accepted: 18 February 2020 